\title{
Traumatic aniridia in a pseudophakic patient 6 years following surgery
}

This article was published in the following Dove Press journal:

Clinical Ophthalmology

10 February 2012

Number of times this article has been viewed

Mikel Mikhail'

Keyvan Koushan ${ }^{2}$

Rajeshvar K Sharda ${ }^{2}$

Gloria Isaza ${ }^{2}$

Keith D Mann²

'Michael G DeGroote School of Medicine, ${ }^{2}$ Division of Ophthalmology, Department of Surgery, McMaster University, Hamilton, ON, Canada
Correspondence: Keyvan Koushan

15 Hawkswood Trail, Hamilton, ON, Canada L9B2P3

$\mathrm{Tel}+$ I 905 973-1816

Fax + I 9053903577

Email kkoushan@gmail.com
Purpose: To report a case of aniridia in a pseudophakic patient following blunt trauma to the eye.

Case report: The traumatized eye had cataract surgery through a $3.0 \mathrm{~mm}$ clear corneal incision 6 years prior to the incident. While there have been previous cases of traumatic aniridia in pseudophakic eyes, previous reports have all occurred closer to the time of the cataract surgery. We believe that the most likely mechanism of loss of iris tissue is through wound dehiscence, which would suggest the relative instability of clear corneal incisions several years postoperatively. The patient's visual acuity returned to 20/20 4 weeks post-trauma, with symptoms of glare which were managed by the use of a colored contact lens.

Conclusion: The possibility of wound dehiscence should be recognized as an important clinical entity in the immediate postoperative period, but also several years following cataract surgery.

Keywords: anirida, pseudophakia, cataract extraction, cataract, phacoemulsification, trauma

\section{Introduction}

Blunt trauma to the eye usually results in anteroposterior compression of the globe leading to its expansion in other meridians due to the severe rise in intraocular pressure. The acute damage to ocular structures include corneal abrasion, hyphema, iridodialysis, subluxation of the lens, commotio retinae, choroidal rupture, retinal detachment, and globe rupture. In a pseudophakic patient, one might add the risk of intraocular lens (IOL) dislocation and wound dehiscence to this list. Traumatic aniridia in the period up to 3.5 years after cataract surgery in eyes with clear corneal incisions has been previously described in the literature..$^{1,2,4-9}$

\section{Purpose}

We present a case of total traumatic aniridia in a pseudophakic patient 6 years after cataract surgery. Despite the safety of clear corneal incisions in modern cataract surgery, surgeons should recognize postoperative wound dehiscence as a rare, yet important, complication that can occur several years following surgery.

\section{Case report}

A previously healthy 66-year-old female presented with decreased vision in her left eye 2 hours after blunt trauma to the eye. She had reportedly hit her left eye against a shelf in her basement. Her past ocular history was significant for bilateral pseudophakia. The cataract surgery on the left eye had been performed through a $2.75 \mathrm{~mm}$ (extended to $3.0 \mathrm{~mm}$ ) 
temporal clear corneal incision 6 years prior to the accident. She received silicon multipiece foldable IOLs (Bausch and Lomb, Rochester, NY) with $6.0 \mathrm{~mm}$ optic silicone lens and PMMA haptics. The overall length of the IOL was $13.0 \mathrm{~mm}$. She also had a history of minimally symptomatic bilateral epiretinal membranes (Figure 1), more significant in the traumatized eye. Examination of her left eye showed visual acuity of hand movement, hyphema of $5.6 \mathrm{~mm}$, and what appeared to be a mydriatic pupil (Figure 2). The corneal wound was Seidel negative, with no evidence of iris tissue at the time of presentation. There was no evidence of IOL decentration or displacement of the haptics. Intraocular pressure (IOP) in the affected eye was $29 \mathrm{mmHg}$. There was dense vitreous hemorrhage obscuring the view of the fundus. The patient was started on timolol $0.5 \%$ twice a day, prednisolone acetate $1 \%$ four times a day, and cyclopentolate $1 \%$ twice a day, and was given instructions on proper head positioning. The patient was also instructed to apply a shield on the affected eye while sleeping. Ultrasound biomicroscopy (B-scan) revealed vitreous hemorrhage but there was no retinal detachment. In subsequent visits, visual acuity, hyphema, and IOP improved. The hyphema and vitreous hemorrhage eventually resolved in 4 weeks with visual acuity returning to 20/20. During this period, as the blood was subsiding, absence of the iris was noted (Figure 1). Gonioscopy revealed no iris tissue and no iris remnants. The patient opted for coloured contact lenses to relieve symptoms of glare and photophobia, as well as cosmetic improvement. Prior photographs, surgeon's notes, as well as the patients' own account all indicated no iris abnormality prior to the traumatic incident.

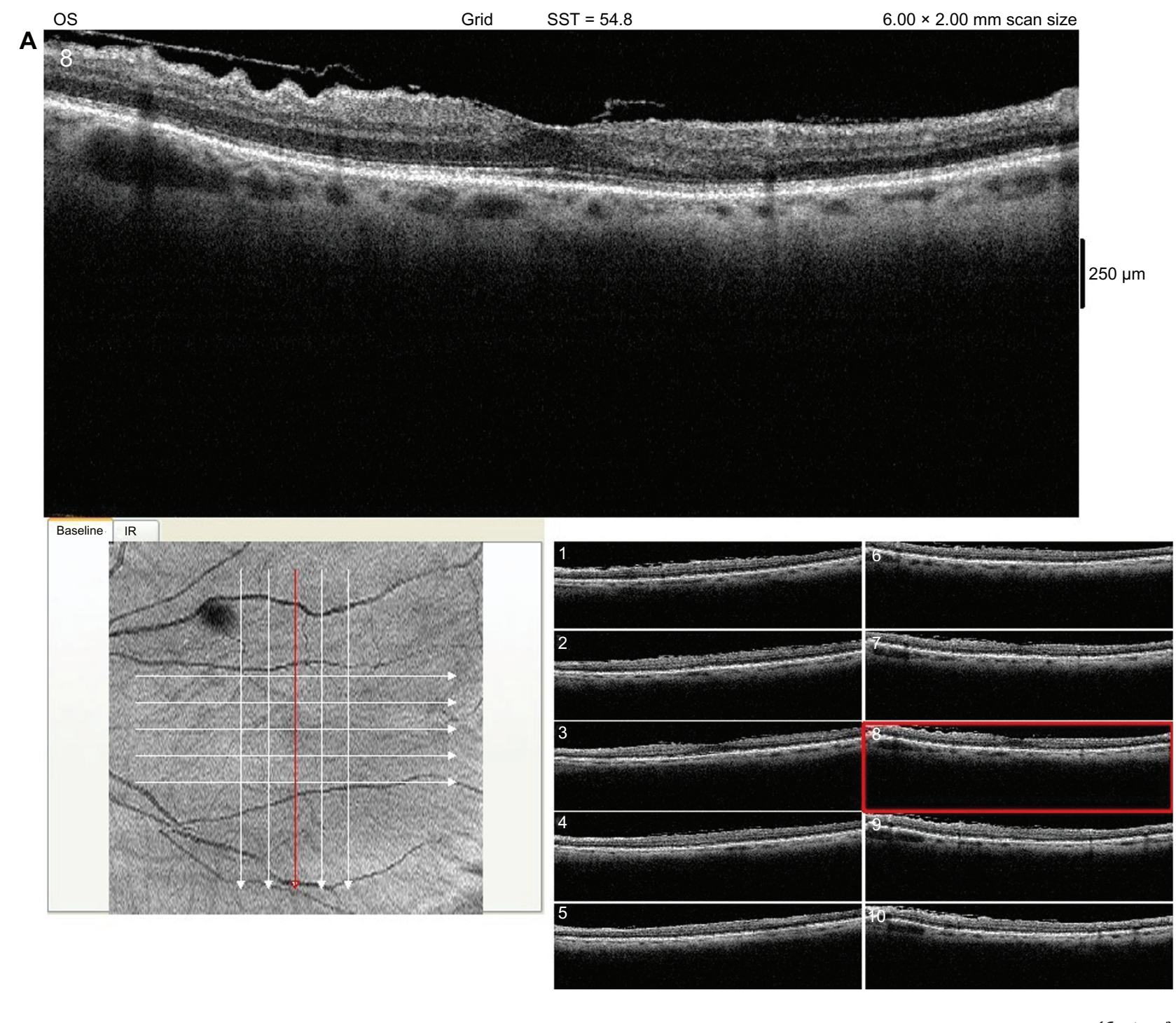

(Continued) 


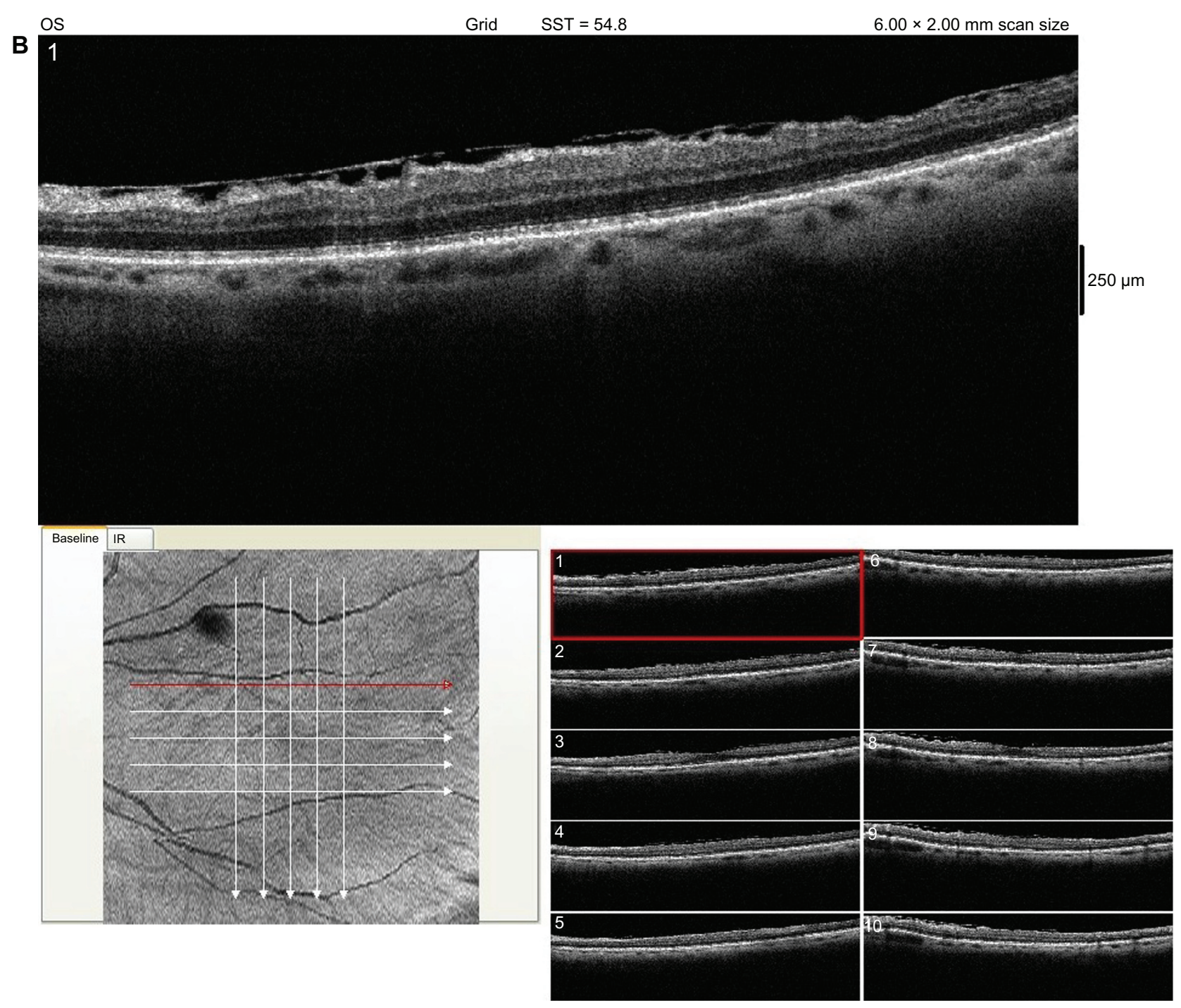

Figure I Posterior Segment Optical Coherence Tomography (OCT) of the left eye revealing an epiretinal membrane.

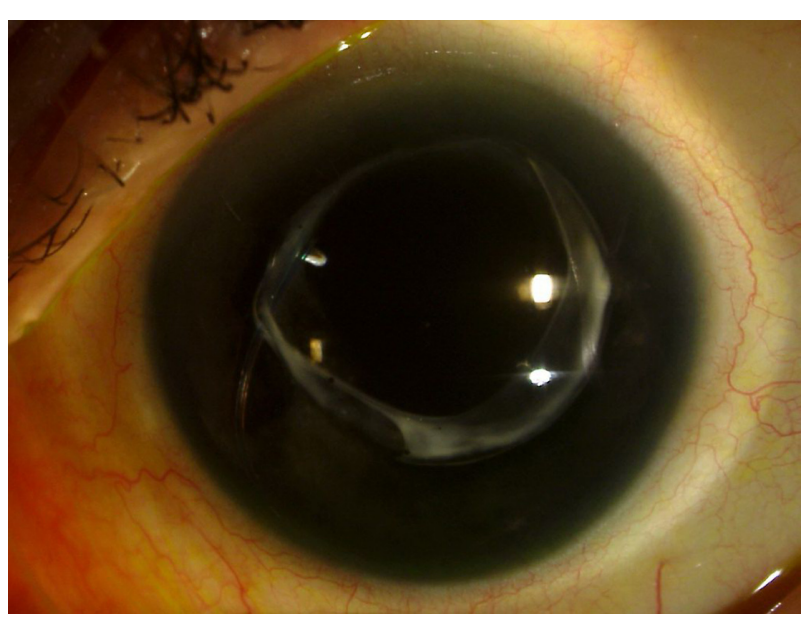

Figure 2 Slit lamp photograph of the left eye.

\section{Discussion}

Aniridia following trauma in pseudophakic patients who have undergone phacoemulsification has been previously reported in the literature. Ball et al reported the first such case occurring 12 months postoperatively. ${ }^{1}$ Hurvitz also reported traumatic iris prolapse in a 72 -year-old patient through a clear corneal incision 3 years postoperatively. ${ }^{10}$ Routsis and Garston presented a case of almost complete absence of iris following trauma to an eye that had undergone scleral tunnel phacoemulsification 3.5 years before. ${ }^{3}$ On examination, our patient had complete aniridia following an accident 6 years following phacoemulsification through a clear corneal incision.

A number of explanations have been postulated for pseudophakic traumatic aniridia. Ball et al provided three 
possible mechanisms: iris tissue remaining in the anterior chamber, escaping through a new traumatic wound or prolapsing through a previously constructed surgical incision that subsequently dehisced upon trauma. ${ }^{1}$ In our case, there was an acute rise in intraocular pressure and there was no evidence of globe rupture on examination, making the possibility of iris expulsion through a new wound less plausible. Alternatively, the ruptured iris could have remained in the anterior chamber. Ultrasound biomicroscopy of a similar case showed echogenic particles along the anatomic iris position. ${ }^{6}$ These findings would explain ischemic necrosis and subsequent phagocytosis of iris tissue.

We believe that, in our case, the most likely explanation is dehiscence of the self-sealing clear corneal incision used for phacoemulsification and IOL implantation 6 years prior to the accident. Ball et al argues that complete iridectomy is more likely to occur in small-incision cataract surgery than in extracapsular cataract extraction. ${ }^{1}$ In blunt trauma, the smaller incision is more likely to dehisce at a higher intraocular pressure than the larger wound of extracapsular cataract extraction. The deficiently healed corneal incision acts as a release valve in the setting of a sudden increase in intraocular pressure. Despite iris extrusion, the release valve mechanism prevents rupture at the limbus or the rectus muscle insertions. This potentially results in less damage to the intraocular structures than would otherwise be expected for unoperated eyes experiencing the same degree of trauma. Preservation of the IOL could also prevent the extrusion of posterior segment contents. In our case, there was no evidence of IOL decentration or subluxation. In a previous case of total traumatic aniridia, ultrasound biomicroscopy showed preservation of the zonular architecture as well as Descemet's membrane loss along the corneal wound track. ${ }^{7}$ The latter would provide further evidence of dehiscence of the surgical incision.

The healing of clear corneal incisions is typically slower than scleral and limbal wounds. Ernest et al demonstrated that rectangular clear corneal incisions in feline eyes were less resistant to deformation than limbal incisions. ${ }^{11}$ Corneal incisions took 60 days to heal, while limbal incision healing occurred within 7 days due to the fibrovascular response. This would suggest relative instability in the immediate postoperative period, but does not have implications on the stability of clear corneal incisions several years following surgery. In Mackool and Russell's work, ${ }^{12}$ clear corneal incisions which were $3.0 \mathrm{~mm}$ or less in length, and greater than $2.0 \mathrm{~mm}$ in width were equally resistant to deformation, as were scleral tunnels in human cadaver eyes. In most other cases reported in the literature, iris prolapse occurred through clear corneal incisions that were greater than $3.0 \mathrm{~mm}$. Kahook and $\mathrm{May}^{8}$ reported a case of total iridectomy in an operated eye with a $3.0 \mathrm{~mm}$ clear corneal incision and Walker et $\mathrm{al}^{9}$ also reported iridectomy post-traumatically in an eye that had been operated on through a $3.2 \mathrm{~mm}$ clear corneal incision. Unlike our case, however, both events occurred comparatively close to the time of surgery, at 3 months and 10 weeks, respectively.

Symptoms of aniridia range from decreased visual acuity to photophobia and incapacitating glare, as well as cosmesis-related problems. Chromatic and spherical aberration as well as the Stiles-Crawford effect are also associated with aniridia. A number of options exist for resolving the symptoms of glare that could accompany aniridia. These include the use of coloured contact lenses, corneal tattooing, or iris reconstruction implants (IRI). Although our patient opted for a colored contact lens, the implantation of an IRI is also a possibility. In the setting of pseudophakia, the insertion of an IRI would require re-opening of the capsular bag by viscodissection. In cases of complete aniridia, Burk used two endocapsular-ring-style multi-finned devices that interdigitated in the capsular bag to create a diaphragm that replaced the lost iris. ${ }^{13}$

In an attempt to reduce the incidence of traumatic dehiscence of the corneal wound postoperatively, the surgeon must ensure wound integrity. This involves fashioning a well-constructed square corneal incision and using stromal hydration for wound closure. If the surgeon is particularly concerned about wound integrity or postoperative wound leak, he or she should suture the wound to ensure closure. Intra-operatively, the surgeon should also avoid iris prolapse by reducing the pressure gradient during phacoemulsification when appropriate.

While clear corneal incisions used for small-incision cataract surgery are generally considered self-sealing and secure, the possibility of wound dehiscence with prolapse of anterior chamber contents should be recognized as an important clinical entity postoperatively. This is particularly the case in the immediate period following surgery when the wound is most susceptible to dehiscence, as well as several years post-phacoemulsification as highlighted in our case.

\section{Disclosure}

The authors have no financial interests in the subject matter of this presentation. There were no sources of public or private support in completing this study. 


\section{References}

1. Ball J, Caesar R, Choudhuri D. Mystery of the vanishing iris. J Cataract Refract Surg. 2002;28(1):180-181.

2. Lim JI, Nahl A, Johnston R, Jarus G. Traumatic Total Iridectomy Due to Iris Extrusion through a self-sealing Cataract Incision. Arch Ophthalmol. 1999; 117:542-543.

3. Routsis P, Garston B. Late traumatic wound dehiscence after phacoemulsification. J Cataract Refract Surg. 2000;26(7):1092-1093.

4. Lee SJ. Traumatic aniridia and aphakia after Artisan intraocular lens implantation. J Cataract Refract Surg. 2007;33(7):1341-1342.

5. Prabhu A, Nayak H, Palimar P. Traumatic expulsive aniridia after phacoemulsification. Indian J Ophthalmol. 2007;(55):232-233.

6. Parmeggiani F. Trauma of a Pseudophakic Eye. Ultrasound. 2007;26:1795-1797.

7. Doro D, Deligianni V. Ultrasound biomicroscopy in traumatic aniridia 2 years after phacoemulsification. J Cataract Refract Surg. 2006;32(10):1753-1755.
8. Kahook MY, May MJ. Traumatic total iridectomy after clear corneal cataract extraction. J Cataract Refract Surg 2005;31(8):1659-1660.

9. Walker NJ, Foster A, Apel AJ. Traumatic expulsive iridodialysis after small-incision sutureless cataract surgery. J Cataract Refract Surg. 2004;30(10):2223-2224.

10. Hurvitz LM. Late clear corneal wound failure after trivial trauma. J Cataract Refract Surg. 1999;25(2):283-284.

11. Ernest P, Tipperman R, Eagle R, et al. Is there a difference in incision healing based on location? J Cataract Refract Surg. 1998; 24(4):482-486.

12. Mackool R, Russell R. Strength of clear corneal incisions in cadaver eyes. J Cataract Refract Surg. 1996;22(6):721-725.

13. Burk S. Prosthetic iris implantation for congenital, traumatic, or functional iris deficiencies. J Cataract Refract Surg. 2001;27(11):1732-1740.
Clinical Ophthalmology

\section{Publish your work in this journal}

Clinical Ophthalmology is an international, peer-reviewed journal covering all subspecialties within ophthalmology. Key topics include: Optometry; Visual science; Pharmacology and drug therapy in eye diseases; Basic Sciences; Primary and Secondary eye care; Patien Safety and Quality of Care Improvements. This journal is indexed on

Submit your manuscript here: http://www.dovepress.com/clinical-ophthalmology-journal

\section{Dovepress}

PubMed Central and CAS, and is the official journal of The Society of Clinical Ophthalmology (SCO). The manuscript management system is completely online and includes a very quick and fair peer-review system, which is all easy to use. Visit http://www.dovepress.com/ testimonials.php to read real quotes from published authors. 